

\title{
Active wideband antenna for underwater tomography (1 $\mathrm{GHz})$
}

Christophe Conessa, Alain Joisel

\section{To cite this version:}

Christophe Conessa, Alain Joisel. Active wideband antenna for underwater tomography $(1 \mathrm{GHz})$. Electronics Letters, 2009, 45 (4), pp.193-194. 10.1049/el:20093275 . hal-00442139

\section{HAL Id: hal-00442139 \\ https://hal.science/hal-00442139}

Submitted on 18 Dec 2009

HAL is a multi-disciplinary open access archive for the deposit and dissemination of scientific research documents, whether they are published or not. The documents may come from teaching and research institutions in France or abroad, or from public or private research centers.
L'archive ouverte pluridisciplinaire HAL, est destinée au dépôt et à la diffusion de documents scientifiques de niveau recherche, publiés ou non, émanant des établissements d'enseignement et de recherche français ou étrangers, des laboratoires publics ou privés. 


\title{
Active wide band antenna for under water tomography $(1 \mathrm{GHz})^{1}$
}

\author{
C.Conessa and A.Joisel
}

A new active antenna has been designed to measure electromagnetic fields in water. It combines a differential wideband amplifier and a dipole, whose characteristics have been designed to provide a constant gain on the bandwidth of the antenna. The small size of the dipole reduces the mask effect. The designed antenna is a symmetrical reception antenna for the electromagnetic field measurement in water in the frequency range of $100 \mathrm{MHz}$ to $1 \mathrm{GHz}$ and it introduces few disturbances. A possible application will be the microwave imaging of immersed objects.

Introduction: This study was launched in order to reduce field measurement disturbances due to the presence of a receiving antenna in the vicinity of the immersed object to be characterized (Figure 1). When the receiving antenna is placed between the transmitter and the object under test, it results in a "mask effect". Our experimental set-up consists of a large water tank, two wideband biconic antennas [1] (transmission and reception), and a step-bystep motor for positioning control of the receiving antenna in order to obtain a synthetic antenna array. Our goal is to realize the equivalence of a sonar system for electromagnetic waves which characterizes immersed objects. Nevertheless, due to its size, the receiving antenna causes a mask effect when it is located between this immersed object and the transmitting antenna, leading to mismatches between the model and experimental data which affect

\footnotetext{
${ }^{1}$ Initiate on a demand from the GESMA (Groupe d'Etude Sous-Marine de l'Atlantique)
} 
the images reconstructions. In order to reduce these mismatches, a new antenna which introduces a smaller mask effect has been developed. A similar approach has been used for astronomical studies [2]. As uncommonly under water near-field measurements are not well studied, a first investigation of such systems has been done.

Antenna development: Using a short dipole instead of a thick wide band conventional antenna allows the mask effect to be reduced drastically. This dipole can be connected to a differential amplifier which is used as a wideband matching network and ideal balun. A short antenna $(I<<\lambda)$ presents two advantages: i) its omnidirectional pattern is quite independent of the frequency and ii) this antenna works like a field measurement device over a wide frequency band, while the drawbacks are i) the impedance of the dipole varies greatly with the frequency and ii) it has poor sensitivity specially for the low frequencies. Hence the dipole is connected to a high input impedance differential amplifier which acts as a perfect wide band balun.

Also, we calculated the length of the dipole to have the resonance frequency near the end of the amplifier's bandwidth at $900 \mathrm{MHz}$. AD8351, a CMS integrated circuit is selected for the amplification as it has a differential input and a stable gain between 1 to $1000 \mathrm{MHz}$. Moreover, its small size $(2.1 \mathrm{~cm})$ means that less disturbance is introduced to the system.

For practical reasons, a short transmission line is needed to connect the dipole to the amplifier input. The impedance of this line is $73 \Omega$, matched to the dipole only at the resonance frequency. As the dipole and the amplifier impedances are not matched to the transmission line over the operating 
frequency band, it is necessary to adjust the length of this line to minimize mismatch effects. In order to optimize the length of the line, the equivalent circuit of the "antenna-line-amplifier" system (Figure 2) has been simulated using Matlab. The impedance $Z_{a}$ of the antenna is given by Johnson and Jasik model [3].

$$
Z_{a}=R(k l)-\mathrm{j}\left[120\left(\ln \frac{l}{a}-1\right) \cot k l-X(k l)\right]
$$

Where :

$Z_{a}$ is the impedance in ohms of a dipole which is a cylinder with a length of $I=I / 2$ and a radius of $a$.

$k l=2 \pi(I / \lambda)$ (in radians) is an electric length and the functions $R(k l)$ and $X(k l)$ given by [3]. The amplifier input impedance are given by data sheet of the selected integrated circuit [4]. The amplifier input is taken to be a $5 \mathrm{k} \Omega$ resistance in parallel with a $0.8 \mathrm{pF}$ capacitor.

The transfer function of the system between the dipole connection and the device output is :

$$
T(j \omega)=\frac{Z_{e}}{Z_{e}+Z_{a, L}} \sqrt{\frac{\operatorname{Re}\left(Z_{a, L}\right)}{\operatorname{Re}\left(Z_{a}\right)}}
$$

Where $Z_{e}$ is the input impedance of the amplifier given by:

$$
Z_{e}=\frac{R_{e}}{1+j R_{e} C_{e} \omega}
$$

And $Z_{a, L}$ is the impedance measured at a given position $L$ from the dipole trough the line between the amplifier input and the antenna and it is given by :

$$
Z_{a, L}=Z_{d} \frac{Z_{a}+j Z_{d} \tan (\beta L)}{Z_{d}+j Z_{a} \tan (\beta L)}
$$

Where $Z_{d}$ is the characteristic impedance of the line $(73 \Omega)$, $\beta=\frac{2 \pi}{\lambda}$ is the propagation constant and $L$ is the length of the line. 
With these elements, we study the influence of the line on the gain of the transfer function $\mathrm{T}(\mathrm{j} \omega)$.

As we can see in Figure 3, the gain is higher when $L$ is small.

In order to keep a constant gain over the whole operating bandwidth and to have an easier realization, a length of two centimeters is chosen. In this case, the gain is between $-10 \mathrm{~dB}$ to $-5 \mathrm{~dB}$.

Structure of the line:

To obtain the desired impedance, simulations using CST microwave studio are done to study different structures. Following Transmission Line Design Handbook [5], the coplanar guide with ground is selected as the most appropriate solution (Figure 4). With $w=2.4 \mathrm{~mm}$ and $d=s=0.5 \mathrm{~mm}$, an impedance of $72.8 \Omega$ is obtained.

Antenna test: First, we test the antenna in air inside an anechoic chamber. The length of the dipole is set to be half of the wavelength of the transmitted signal $(I=18 \mathrm{~cm})$. The gain versus the frequency has been confirmed although there are some losses. Next the length of the dipole is reduced to take into account the permittivity of water. In this case, it is difficult to be under the same conditions as in the anechoic chamber. Hence the transmission coefficient from the transmitter to the receiver for the active and the biconic antennas have been investigated (Figure 5). This study shows that the bandwidth is improved using the active antenna in underwater propagation. The new bandwidth is around 600 to $800 \mathrm{MHz}$. Moreover, we have a better sensitivity especially for high frequencies. 
Conclusion: This study opens the path to new developments. The new active probe (Figure 6) is smaller than the biconic system, hence resulting in less disturbance. Its gain is also higher than the former system. Simple, cheap and easy to build, becomes possible to build an antenna array for immersed object imaging with low disturbance. The sensitivity is also better especially for high frequencies. As a consequence the spatial resolution of tomographic systems using such probes can be improved. Before realizing a probe array using this principle, the prototype could be improved, by optimizing other parameters such as dipole and differential line lengths.

\section{References}

1 Duchêne, B. and Joisel, A. and Lambert, M., "Nonlinear inversions of immersed objects from laboratory-controlled data, Inverse Problems, Special section on the Electromagnetic Characterization of Buried Obstacles", D. Lesselier and W. C. Chew Eds., 2004, 20, 6, S81-S98, December 2 Ardouin, D.; Bellétoile, A.; Charrier, D.; Dallier, R.; Denis, L.; Eschstruth, P.; Gousset, T.; Haddad, F.; Lamblin, J.; Lautridou, P.; Lecacheux, A.; Monnier-Ragaigne, D.; Rahmani, A.; Ravel, O., "Radiodetection signature of high-energy cosmic rays by the CODALEMA experiment', 2005 december, Nuclear Instruments and Methods in Physics Research Section A, Volume 555, Issue 1-2, p. 148-163,

3 R. JOHNSON, H. JASIK, "Antenna Engineering Handbook, second edition", 1993, Mc Graw Hill Publication

4 ANALOG DEVICES, "Low Distortion, Differential RF/IF Amplifier, AD8351", Rev. B, 2003.

$5 \quad$ BRAIN C. WADELL, "Transmission Line Design Handbook", 1991

June, Artech House Publishers

\section{Authors' affiliations:}

C. Conessa and A. Joisel (Department of Electromagnetic Research,

\section{L2SICNRS)}

\section{Authors' emails:}

Christophe.conessa@1ss.supelec.fr

Alain.joisel@1ss.supelec.fr 


\section{Figure captions:}

Figure 1 : Experimental setup

Figure 2 : Equivalent circuit for the system "antenna-line-amplifier"

Figure 3 : Influence's study of the line's length on the gain versus frequency

Figure $4:$ Structure of the differential line

Figure 5 : Transmission coefficients comparison between influence's study of the line's length on the gain versus frequency

Figure 6 : Active antenna photos 
Figure 1

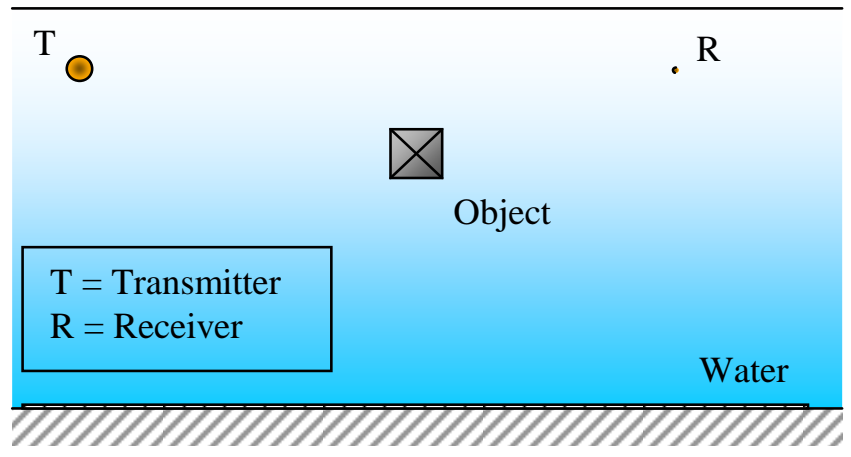


Figure 2

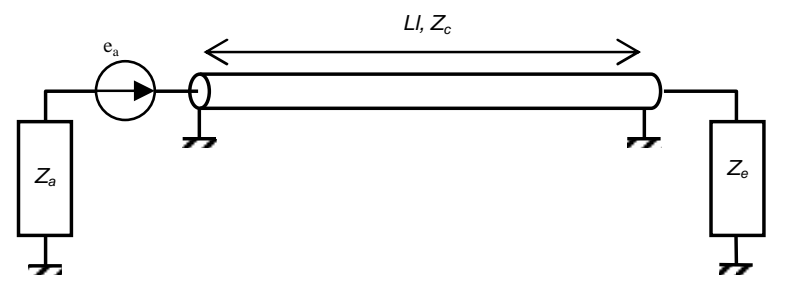


Figure 3

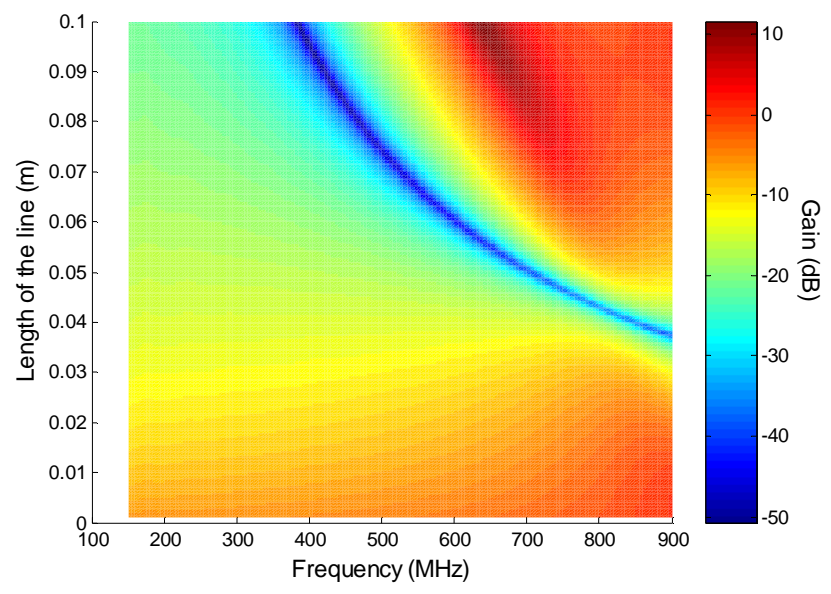


Figure 4

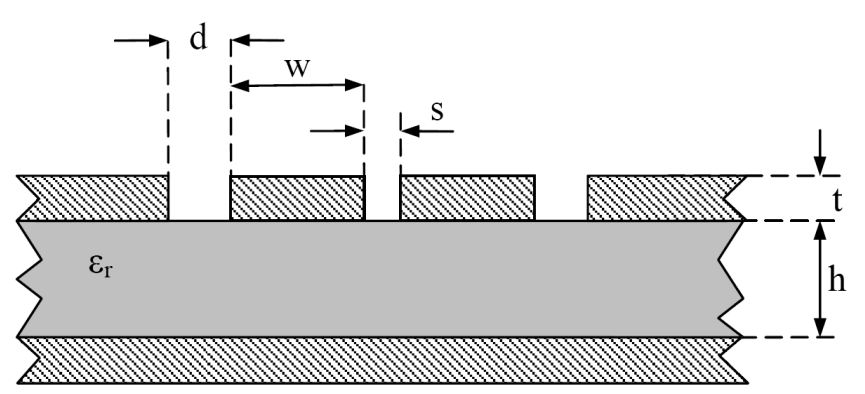


Figure 5

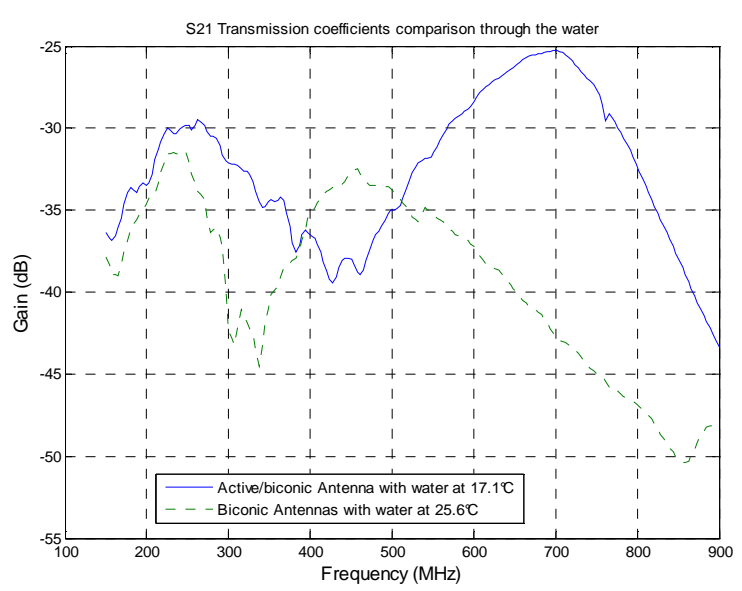


Figure 6

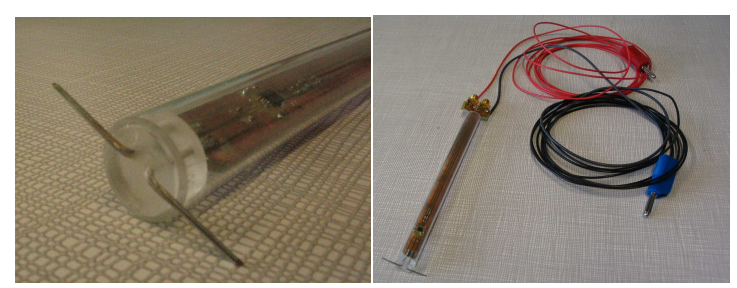

